\title{
A RESPOSTA DE RAWLS À CRÍTICA DE SCHOPENHAUER AO PRINCÍPIO MÁXIMO DA ÉTICA DE KANT
}

\author{
Charles Feldhaus \\ Universidade Estadual de Londrina
}

Resumo: Esse estudo pretende reconstruir e examinar a resposta de Rawls à objeção desfechada por Schopenhauer à ética de Kant, em Über die Grundlage der Moral, §7, de que o que discrimina entre o moralmente correto e o moralmente incorreto é, no final das contas, o egoísmo e não qualquer tipo de contradição na universalização, em suas obras $A$ Theory of Justice e Political Liberalism, também afeta à justiça como equidade.

Palavras-chave: ética, egoísmo, universalidade, reciprocidade, ética da compaixão.

Abstract: This study aims to reconstruct and examine the response to the objection throw against ethics of Kant by Schopenhauer in the $§ 7$, Über die Grundlage der Moral, that is, discriminates between morally right and wrong is, after all, selfishness and not any kind of contradiction in the universalization of the maxims, in the works of Rawls $A$ Theory of Justice and Political Liberalism, also affects to the justice as fairness.

Keywords: ethics, selfishness, universality, reciprocity, ethics of compassion.

\section{Introdução}

Arthur Schopenhauer (1788-1860), em sua obra Über die Grundlage der Moral, além de tentar desenvolver sua própria concepção de moralidade baseada na compaixão, empreende várias críticas à ética de Immanuel Kant (1724-1804), desenvolvida em sua obra Grundlegung der Metaphysik der Sitten, Kritik der praktischen Vernunft e Die Metaphysik der Sitten. Algumas das críticas schopenhaurianas ecoam aquelas já realizadas por G. W. Hegel, em suas obras Grundlinien der Philosophie der Rechts, como a objeção do formalismo vazio (§ 135). Não obstante, alguns pensadores contemporâneos têm tentado reabilitar uma concepção normativa na ética e na política 
supostamente inspirada na filosofia prática de Kant, como é o caso de Jürgen Habermas e John Rawls. Esse último sustenta que sua concepção de justiça, a qual denomina de justiça como equidade (justice as fairness) é inspirada no construtivismo moral de Kant, tal como o filósofo de Königsberg desenvolve em sua obra Grundlegung der Metaphysik der Sitten. A principal diferença entre o construtivismo kantiano e o rawlsiano refere-se, no entender do próprio Rawls (RAWLS, 1993, p. 99), em que o primeiro é baseado em ideias oriundas de concepções abrangentes de bem, ao passo que o último se baseia apenas em ideais políticas compartilhadas pelas sociedades democráticas e liberais contemporâneas e, por isso Rawls denomina seu construtivismo de político ${ }^{1}$. Habermas, por sua vez, também procurou desenvolver uma concepção normativa baseada nos passos de Kant, a que chamou de ética do discurso, e, além disso, ele procurou responder se sua reformulação da ética kantiana era suscetível às críticas de tipo hegeliano em sua obra Erläuterung zur Diskursethik. Rawls também se detém em Political Liberalism (PL) a responder se a justiça como equidade seria afetada pelas críticas hegelianas (PL, VII, §10, 285ss) e pelas críticas schopenhauerianas (PL, III, §3, 104-7 ; TJ, $\S 25,127-8$ ) à ética kantiana. À resposta de Rawls às últimas que esse estudo pretende reconstruir e avaliar.

No que segue, primeiramente, será reconstruída a crítica de Schopenhauer à ética de Kant de o que discrimina entre o certo e o errado é o egoísmo e não uma suposta impossibilidade de universalizar máximas imorais; em segundo lugar, serão realizadas algumas considerações acerca da necessidade de ele ter realizado um grande esforço em procurar responder a essa objeção assim como será reconstruída a própria objeção de Schopenhauer; em seguida serão realizadas algumas aproximações da ética schopenhaueriana e da ética de virtudes; finalmente, serão feitas considerações a respeito da pertinência da resposta de Rawls às objeções schopenhauerianas tratadas aqui.

\section{A crítica de Schopenhauer ao princípio supremo da ética de Kant}

Rawls se refere à crítica que Schopenhauer desfecha, contra a ética de Kant, no §7 cujo título é Vom obersten Grundsatz der Kantischen Ethik, do livro Über die Grundlage der Moral, o pensador alemão começa afirmando que o imperativo categórico, em sua fórmula da universalidade, não é ele mesmo o

\footnotetext{
1 Não faz parte dos objetivos do presente estudo avaliar se Rawls interpreta corretamente a filosofia moral de Kant como construtivista e nem se faz sentido derivar uma concepção política de uma teoria desenvolvida para tratar de problemas especificamente morais.
} 
critério ético de Kant, mas antes, apenas uma regra heurística. O imperativo categórico em sua primeira formulação "não é dinheiro vivo, mas uma ordem de pagamento segura. Quem é que deve propriamente pagá-la? Para dizer a verdade francamente: um tesoureiro aqui bem inesperado, que outro é senão o egoísmo" (SCHOPENHAUER, 2001, p. 68; 2007, p. 53)2. O que Schopenhauer afirma é o que pretendemos agora mostrar.

Segundo Schopenhauer (SCHOPENHAUER, 2001, p. 68-9; 2007, p. 54) na filosofia moral kantiana estaria envolvida uma pressuposição tácita de "que só posso querer aquilo com que me dou melhor." Ou seja, ao examinar se existe alguma contradição envolvida na universalização de uma máxima imoral, é preciso adotar não apenas o papel da parte ativa, mas também da parte passiva, no curso de ação sob avaliação. Schopenhauer afirma que a impossibilidade de pensar ou querer uma máxima como lei universal da natureza é garantida não pela simples universalização do princípio subjetivo do querer, mas antes, pelo egoísmo, pelo receio de tornar-se a parte passiva, que sofre o ato orientado pela máxima supostamente imoral, e isso seria válido para o dever de veracidade, de fazer beneficência, etc. O que, segundo Schopenhauer (SCHOPENHAUER, 2001, p. 70; 2007, p. 55) ${ }^{4}$, Kant deixa mais evidente em Die Metaphysik der Sitten (Tugendlehre, §30, 453), que o imperativo categórico baseia-se no egoísmo e é, no final das contas, um tipo de regra de reciprocidade camuflada, a saber, eu devo fazer beneficência a fim de que não prive a mim mesmo da ajuda das outras pessoas, da qual eu posso vir a precisar. Schopenhauer (SCHOPENHAUER, 2001, p. 70; 2007, p. 55) ${ }^{5}$ sustenta que a reciprocidade seria um princípio adequado para a fundamentação do Estado, mas nunca para a fundamentação das regras éticas. E, se isso for a interpretação correta do que está envolvido no teste de universalidade da máxima kantiana, então afirma Schopenhauer:

A partir dessa explicação fica totalmente claro que aquela regra fundamental kantiana não é, como ele afirma

\footnotetext{
2 "also gleichsam zwar noch nicht baares Geld, aber eine sichere Anweisung. Wer nun ist es eigentlich, der diese realisieren soll? Die Wahrheit gleich heraus zu sagen: ein hier sehr unerwarteter Zahlmeister: Niemand anders als der EGOISMUS; wie ich sogleich deutlich zeigen wurde."

3 "Die in KANTS oberter Regel enthaltene Anweisung zur Auffindung des eigentlichen Moralprincips beruht nämlich auf der stillschweigenden Voraussetzung, dass ich nur DAS wollen kann, wobei ich mich am besten stehe."

4 "Also ist hier so deutlich, wie nur immer möglich, ausgesprochen, dass die moralische Verpflichtung ganz und gar auf vorausgesetzter RECIPROCITÄT beruht, folglich schlechthin egoistisch ist und vom Egoismus ihre Auslegung erhält, as welcher, unter der RECIPROCITÄT, sich klüglich zu einem Kompromiss versteht."

5 "Zur Begründung des Princips des Staatsvereins wäre das tauglich, aber nicht zu der des Moralprincips."
} 
incansavelmente, um imperativo categórico, mas sim um imperativo hipotético, pois no seu fundamento jaz tacitamente a condição de que a lei que se estabelece para meu agir, já que eu a elevo a universal, também torna-se lei para o meu padecer, e eu, eventualmente como parte passiva, não posso simplesmente querer injustiça e falta de caridade. (SCHOPENHAUER, 2001, p. 71; 2007, p. 56) ${ }^{6}$

Se essa interpretação do teste de moralidade das máximas kantiano for adequada, ele tem o inconveniente que, diz Schopenhauer (SCHOPENHAUER, 2001, p. 71; 2007, p. 56) ${ }^{7}$, se parto da suposição que sempre posso ser a parte ativa, a saber, aquele que estaria em condição de fazer a beneficência e não aquele que está na condição de precisar da beneficência alheia (a parte passiva), "poderia então muito bem, ao escolher a máxima de validade universal, (...) querer a injustiça e a falta de caridade como máximas universais", ou seja, o princípio supremo da ética de Kant seria incapaz de discriminar o moralmente correto do incorreto e seria por isso vazio de conteúdo, ao menos em sua primeira formulação.

Desse modo, diz Schopenhauer (SCHOPENHAUER, 2001, p. 72; 2007, p. 56) ${ }^{8}$, a ética de Kant carece de uma 'fundamentação real do princípio supremo da moral', oculta a 'natureza hipotética' do princípio moral, uma vez que o mesmo 'se baseia no puro egoísmo' e, por conseguinte, o imperativo categórico kantiano é senão uma "perífrase, um ornamento, uma expressão floreada da regra [de ouro] (...) quod tibe fieri non vis, alteri ne feceris". É importante ressaltar que o próprio Kant defendeu na segunda

\footnotetext{
6 "Aus dieser Erklärung ist vollkommen klar, dass jene Kantische Grundregel nicht, wie er unablässig behauptet, ein KATEGORISCHER, sondern in der That ein HYPOTHETISCHER Imperativ ist, indem demselben stillschweigend die BEDINGUNG zum Grunde liegt, dass das für mein HANDELN aufzustellegende Gesetz für mein LEIDEN wird, und ich unter dieser Bedingung, als der eventualiter PASSIVE Theil, Ungerechtigkeit und Lieblosigkeit allerdings NICHT WOLLEN KANN.".

7 "Hebe ich aber diese Bedingung auf und denke mich, etwan im Vertrauen auf überlegenen Geistes- und Leibeskräfte, stets nur als den AKTIVEN und nie als den PASSIVEN Theil, ber der zu erwählenden allgemein gültigen Maxime; so kann ich, vorausgesetzt dass es kein anderes Fundament der Moral, als das Kantische...".

8 "Also zu dem in vorigen Paragraph dargelegten Mangel an realer BEGRÜNDUNG des Kantischen obersten Grundsatzes der Moral gesellt sich, KANTS ausdrücklicher Versicherung zuwider, die versteckte HYPOTHETISCHE Beschaffenheit desselben, vermöge deren er sogar auf blossen EGOISMUS basiert ist, als welcher der geheime Ausleger der in demselben gegebenen Weisung ist. Hiezu kommt nun ferner, dass er, bloss als Formel betrachtet, nur eine Umschreibung, Einkleidung, verblümter Ausdruck der allbekannten Regel quod tibi fieri non vis, alteri ne feceris ist, wenn man nämlich diese, indem man sie ohne non und ne wiederholt, von dem Makel befreit, allein die Rechts- und nicht die Liebespflichten zu enthalten."
} 
seção da Grundlegung der Metaphysik der Sitten (A.A. VI, 430) que o imperativo categórico não deve ser confundido com a regra de ouro supracitada. Segundo Kant, o que diferencia o imperativo da regra de ouro é, primeiramente, que essa regra, ao contrário do imperativo categórico, não pode ser uma lei universal, dado que trata-se claramente de um imperativo hipotético (por conseguinte, condicional); em segundo lugar, por não poder ser uma lei universal, é incapaz de conter deveres incondicionais, "porque muitos renunciariam de bom grado a que os outros lhes fizessem bem se isso os dispensasse de eles fazerem bem aos outros". Entretanto, supera os objetivos do presente estudo buscar examinar a pertinência ou não, quer da crítica de Schopenhauer à própria ética de Kant, quer da suposta resposta de Kant ao sustentar a não identidade entre o imperativo categórico e a regra de ouro. Além disso, cabe agora indagar qual o problema, supondo que a interpretação schopenhaueriana do teste de universalização kantiano aqui seja adequada, em Kant basear a moralidade no egoísmo. Acredito que aqui há algumas leituras possíveis: primeiramente, Schopenhauer pode estar acusando Kant de inconsistência por um de dois motivos: a) afirmar que o que garante a moralidade e a imoralidade da ação é o teste da universalidade, mas de fato é um cálculo interesseiro e egoísta; b) ao se comprometer com o egoísmo, Kant estaria incorrendo em inconsistência com sua tentativa de fundamentar a moralidade sem recorrer ao eudaimonismo (o que o próprio Schopenhauer tanto havia exaltado na ética de Kant no início do $\S 3$ de Über der Grundlage der Mora $)^{9}$; em segundo lugar, ecoando a crítica hegeliana do formalismo vazio, acusando o princípio máximo de Kant (ao menos a fórmula da universalidade) de ser formalmente vazio.

\section{A resposta de Rawls à objeção de Schopenhauer à ética de Kant}

Agora, entretanto, surge a pergunta: porque Rawls ou seus críticos consideraram que as objeções de Schopenhauer à ética de Kant (a do egoísmo em particular) poderiam criar algum problema à justiça como equidade? Se poderia afirmar que esses críticos perceberam que a teoria da justiça rawlsiana parte de uma situação hipotética, a posição original, em que as partes responsáveis pela escolha dos princípios de justiça que devem reger a estrutura básica da sociedade são dotadas apenas de racionalidade instrumental, ou seja, 'racionalidade prudencial auto-interessada' e, além disso, os mesmos não são mutuamente interessados e além de ser

9 Para Schopenhauer, a compaixão é a única motivação não egoísta e genuinamente moral. (SCHOPENHAUER, 2001, §19, p. 165; 2007, p. 130). 
inconscientes dos laços fortes que possuem com os outros indivíduos da sociedade em que vivem. Isso implicaria, da perspectiva de tais críticos, que a justiça como equidade compreende o indivíduo responsável pela tomada de decisão como egoísta, buscando apenas realizar seus próprios fins subjetivos, e ignorando os interesses compartilhados com os outros indivíduos da sociedade em que vivem (NUSSBAUM, 2003, p. 492). Segundo Nussbaum:

Tais teóricos acusam que, embora as limitações
informacionais do véu de ignorância impeçam às partes de
preferir a si mesmo aos outros em sua escolha dos princípios,
elas mesmas são egoístas, e a teoria de Rawls é nesse sentido
uma teoria egoísta, que gera preocupação com os outros
apenas em função (ouf off) de um conjunto de limitações
externas (NUSSBAUM, 2003, p. 493).

Ou seja, os críticos acreditam que, a despeito de Rawls impor às partes na posição original restrições que procuram garantir que os princípios de justiça serão escolhidos de maneira imparcial (o que ele denomina de restrições do justo), a escolha no fundo é meramente egoísta e as partes raciocinam de modo apenas egoísta, sem interesse mútuo de qualquer tipo. Em outras palavras, assim como a ética de Kant somente consegue discriminar entre o moralmente correto e o moralmente incorreto supostamente baseada no egoísmo e não com base no teste do imperativo categórico, com isso contradizendo sua intenção explícita de mostrar que a moralidade se funda na autonomia da vontade e não na heteronomia, os críticos acreditam que um erro semelhante estaria envolvido no procedimento de escolha dos princípios de justiça na posição original de Rawls. Nussbaum (NUSSBAUM, 2003, p. 492) ${ }^{10}$ sustenta que a crítica é baseada em um equívoco, o que todavia não a torna desinteressante.

Rawls pretende responder à alegação de que a justiça como equidade seria vulnerável às objeções que Schopenhauer desfechou contra a ética de Kant em sua obra Über die Grundlage der Morall, §7, em $A$ Theory of Justice, §25 e Political Liberalism, III, §3. Rawls (RAWLS, 1999, p. 127) afirma que, uma vez que a justiça como equidade, assume que as partes na posição original (a situação hipotética de escolha dos princípios de justiça) não são mutuamente interessadas, ou seja, não possuem nenhum tipo de disposição benevolente para com as outras partes, então, se poderia pensar

10 Nussbaum não explicita exatamente porque ela acredita que a crítica é equivocada. 
que a mesma seria uma teoria egoísta. Esse tipo de objeção, segundo Rawls (RAWLS, 1999, p. 127-8), seria semelhante àquela suscitada por Schopenhauer em sua obra Über der Grundlage der Moral, §7, à ética de Kant, o que o filósofo considera que é um equivoco em relação à justiça como equidade, uma vez que ele observa: primeiramente, mesmo que as partes sejam concebidas como mutuamente desinteressadas na posição original, isso não implica que as pessoas na vida diária precisem ser assim motivadas, a saber, de modo egoísta. Até mesmo porque Rawls (RAWLS, 1999, p. 128) considera que um elemento fundamental, que aumenta a possibilidade de uma teoria de justiça ser escolhida na posição original, é a capacidade da teoria gerar nas pessoas da sociedade, na qual seus princípios regulam a estrutura básica da sociedade (as principais instituições da sociedade), um senso de justiça.

Rawls (RAWLS, 1999, p. 128) acredita que a combinação do véu de ignorância e do desinteresse mútuo das partes consegue obter o resultado da benevolência mútua, o que significa que as partes indiretamente têm um interesse pelos interesses das outras partes contratantes, uma vez que obriga às partes a levar em consideração o bem das outras partes quando da tomada de decisão acerca dos princípios de justiça. Rawls (RAWLS, 1999, p. 129) defende que o sentimento de que a justiça como equidade é egoísta é uma ilusão proveniente de uma ênfase exagerada em apenas um aspecto da posição original, o caráter de desinteresse mútuo das partes contratantes. Além disso, para Rawls (RAWLS, 1999, p. 129), o binômio ignorância e desinteresse mútuo tem vantagens diante do conhecimento e da benevolência.

Como já afirmado, Rawls revisa sua resposta às objeções de Schopenhauer em Political Liberalism. O filósofo estadunidense (RAWLS, 1993, p. 105) afirma em nota que a necessidade de reformulação de sua resposta a esse ponto se deve ao apontamento de Joshua Cohen de que a resposta oferecida em $A$ Theory of Justice não leva em consideração a força da objeção original desfechada por Schopenhauer à ética de Kant. Além disso, Rawls afirma que a resposta oferecida em Political Liberalism melhorou muito em relação à de $A$ Theory of Justice e está conectada com a interpretação revisada da noção de bens primários. Nas próprias palavras de Rawls:

Schopenhauer sustentou que, ao argumentar a defesa do dever de ajuda mútua em situações de necessidade extrema (o quarto exemplo da Grundlegung), Kant apela àquilo que agentes racionais, como seres finitos que têm necessidades, podem coerentemente desejar que seja uma lei universal. (RAWLS, 1993, p. 124). 
Segundo Rawls (RAWLS, 1993, p. 124), a incoerência na universalização de uma máxima cujo conteúdo seja a isenção de realizar atos de amor e compaixão, de beneficência, surge não de uma contradição prática, mas antes de um puro egoísmo, uma vez que Kant estaria partindo da suposição que "não podemos desejar um mundo social no qual os outros sempre sejam indiferentes a nossos pedidos de auxílio, e, por conseguinte, a ética de Kant não seria senão "uma forma disfarçada de heteronomia". Rawls (RAWLS, 1993, p. 125) declara explicitamente que sua intenção não é defender que essa objeção é incorretamente aplicada à ética de Kant, ele nem mesmo entra no mérito dessa questão. Rawls (RAWLS, 1993, p. 125) identifica duas razões motivadoras da objeção de Schopenhauer: 1) ele acredita que o teste de universalização da ética de Kant exige que os princípios subjetivos do querer (as máximas) sejam submetidos à prova à luz das consequências de seu cumprimento em geral às nossas inclinações e necessidades compreendidas de modo egoísta; 2) ele interpreta as regras que definem o procedimento de teste de máximas como restrições externas e não "como derivadas das características essenciais em sua condição de razoáveis." Segundo Rawls (RAWLS, 1993, p. 125), são essas duas características que levaram Schopenhauer a compreender que "o imperativo categórico é um princípio de reciprocidade que o egoísmo astutamente aceita como uma forma de compromisso".

No que segue, Rawls (RAWLS, 1993, p. 125-6) se dedica a examinar se objeção análoga seria correta ou incorretamente aplicada à justiça como equidade. Ele desenvolve sua resposta à objeção de Schopenhauer tentando mostrar como a justiça como equidade se comporta em relação aos dois pontos apresentados anteriormente. No que diz respeito ao primeiro ponto, Rawls afirma que as partes situadas na posição original não têm interesses diretos mutuamente entre si, não obstante, elas compartilham interesses com as pessoas as quais elas representam, e, entre esses interesses ele inclui o que denomina de 'interesses de ordem superior', entre os quais encontram-se o de exercer as duas capacidades morais (concepção de bem e senso de justiça), ou seja, o que exige que as partes decidam buscando assegurar as condições que permitam às pessoas da sociedade promover a concepção de bem que quiserem (obviamente, desde que seja razoável). Rawls (RAWLS, 1993, p. 126) afirma que como "esses interesses determinam as necessidades das pessoas como razoáveis e racionais, os objetivos das partes não são egoístas, e sim de todo apropriados e oportunos. As partes fazem o que representantes fiduciários devem fazer pela pessoa que representam.” O que, segundo ele (RAWLS, 1993, p. 126), contrasta com a visão que Schopenhauer tem da ética de Kant, a saber, que o teste de 
universalização de máxima averigua apenas em que medida podem ser satisfeitas as necessidades e as inclinações naturais egoístas.

No que diz respeito ao segundo ponto, ele (RAWLS, 1993, p. 126) reconhece que as restrições que são impostas às partes na posição original "de fato são externas a elas como agentes racionais de construção, meros personagens artificiais". Não obstante, ele sustenta: "essas restrições expressam o razoável e, por conseguinte, as condições formais implícitas nas faculdades morais dos membros de uma sociedade bem-ordenada, a quem as partes representam.” Para ele (RAWLS, 1993, p. 126), essas restrições procuram garantir uma disposição simétrica entre as partes, e isso contrasta fortemente com essa segunda suposição de Schopenhauer de que "as restrições impostas pelo imperativo categórico derivam dos limites de nossa natureza finita" provenientes de inclinações naturais que deveriam ser superadas. Como diz Rawls: "a objeção análoga à de Schopenhauer não se aplica, e a resposta a isso mostra (...), de que modo a posição original modela a autonomia plena (em contraste com a autonomia racional) dos cidadãos" (RAWLS, 1993, p. 127). Ao afirmar isso, ele remete à discussão da autonomia plena desenvolvida na segunda conferência do Political Liberalism, §6.

Ao tratar do contraste entre autonomia plena e autonomia racional, Rawls afima que a última "é modelada na posição original pela maneira como as partes deliberam como seus representantes", ao passo que a primeira "é modelada pelos aspectos estruturais da posição original, isto é, pela maneira como as partes estão situadas mutuamente e pelos limites à informação a que a deliberação está sujeita” (RAWLS, 1993, p. 77). Com isso, Rawls quer dizer que a autonomia plena não é uma propriedade das partes na posição original, mas apenas dos próprios cidadãos de uma sociedade bem-ordenada em sua vida pública. Ela é um valor político e não um valor ético (RAWLS, 1993, p. 77). Rawls acrescenta que a condição da publicidade (tratada em PL, II, §4) é necessária à realização da autonomia plena. Os aspectos estruturais que modelam a autonomia plena são "as restrições apropriadas sob as quais as partes devem considerar o que conta como boas razões (RAWLS, 1993, p. 78). Nas próprias palavras do autor: "a autonomia plena é expressa agindo de acordo com os princípios públicos de justiça compreendidos como especificando os termos equitativos de cooperação que eles dariam a si mesmos quando situados equitativamente" (RAWLS, 1993, p. 78). Ou seja, é modelada pelas 'condições razoáveis' impostas às partes (RAWLS, 1993, p. 78). A equidade da escolha das partes na posição original é garantida pela ideia de igualdade fundamental como encontrada na cultura política de uma sociedade democrática nos três modos como os cidadãos são considerados como livres (o que fora descrito em PL, I, §5): a) primeiramente, 
os "cidadãos são livres na medida em que se concebem a si mesmos e um ao outro como tendo o poder moral de ter uma concepção de bem" (RAWLS, 1993, p. 30); b) em segundo lugar, os cidadãos "veem-se como livres (...) [porque] se consideram como fontes auto-autenticadoras de pretensões de validade. Isto é "consideram-se como tendo o direito de fazer reivindicações à suas instituições para desenvolver sua concepção de bem" (RAWLS, 1993, p. 32); c) em terceiro e último, os cidadãos se "vêem como livres (...) [porque] são vistos como capazes de tomar responsabilidade por seus fins e isso afeta como várias reivindicações são avaliadas” (RAWLS, 1993, p. 33).

\section{As críticas de Schopenhauer à ética de Kant e a ética de virtudes}

As objeções de Schopenhauer à ética de Kant, em muitos aspectos se assemelham às críticas de pensadores comunitaristas e defensores da ética de virtude à ética de Kant e à justiça como equidade de Rawls. Ele começa o §4 Vom der imperativen Form der Kantischen Ethik, de Über die Grundlage der Moral afirmando que o proton pseudos (a premissa maior que acarreta a falsidade de todo raciocínio) de Kant teria sido o próprio conceito de ética (Ethik), quando sustenta que a filosofia prática (praktischen Philosophie) não diz respeito ao que acontece, mas às leis (Gesetze) do que deve acontecer. Schopenhauer entende que aqui Kant comete uma petitio principii, ou seja, ele entende que Kant precisa justificar e não assumir simplesmente que a filosofia prática trata do 'dever ser' e não apenas do 'ser'. Para ele, a filosofia tem que contentar-se com o esclarecimento e o significado do dado, e não em prescrever às pessoas o que deveria ser feito (SCHOPENHAUER, 2007, p. 18). Kant, segundo Schopenhauer (SCHOPENHAUER, 2007, p. 19), teria herdado a forma imperativa da ética do decálogo mosaico, um conceito que tem significado no contexto da moral teológica, mas não numa moral que se pretende autônoma como a kantiana. É importante lembrar aqui que os defensores da ética de virtudes, principalmente Anscombe e MacIntyre sustentam que a ética iluminista, Kant inclusive, levaram a moral contemporânea a um tipo de desordem, na qual é impossível decidir questões éticas básicas. Em parte, isso se deveria ao abandono da justificação da moral à luz de uma tradição de pesquisa moral, porque o dever somente tem sentido dentro de uma tradição de pesquisa moral.

Ele também afirma que ao recorrer à expressão dever absoluto (absolutes Sollen) Kant comete uma contradictio in adjecto, uma vez que 'dever' na ética é um termo essencialmente relativo e que somente tem significado relacionado com ameaça e castigo (SCHOPENHAUER, p. 21), o que o próprio Kant teria reconhecido, do ponto de vista de Schopenhauer na 
Kritik der praktischen Vernunft, quando recorre, na dialética da razão prática, a discussão do sumo bem com as éticas clássicas (epicurismo e estoicismo) e sustenta a necessidade de postular a existência de Deus e da imortalidade da alma como condição da realização do sumo bem (virtude e felicidade). Por conseguinte, para Schopenhauer, a decisão moral, no fundo, em Kant é baseada apenas na racionalidade instrumental e egoísta, que o conceito de dever somente tem sentido tendo como pano de fundo uma concepção religiosa. Novamente, todos esses elementos estão presentes nas principais propostas da ética de virtude (sem soma de dúvida encontram-se na obra After Virtue de Alasdair MacIntyre e no célebre artigo de G. E. M. Anscombe "Modern Moral Philosophy", de 1958).

Nussbaum, ao tratar da objeção schopenhaueriana à teoria de Rawls aponta também esse paralelo e indica que o problema em ser interpretado como uma concepção moral baseada no egoísmo (obviamente, não se ignora aqui a guinada política empreendida por Rawls em Political Liberalism) encontra-se no comprometimento com uma concepção atomista de pessoa. Mas qual o problema em defender uma visão atomista de pessoa? É verdade, no final das contas, que Rawls defende esse tipo de concepção de pessoa? Defende-se aqui que a resposta a segunda questão é negativa, ou seja, Rawls não defende uma concepção atomista de pessoa, uma vez que supõe que: as partes da posição original tem interesses de ordem superior, de garantir o valor equitativo das liberdades políticas, por exemplo; e, a justiça como equidade opera com um duplo nível de justificação da teoria da justiça, a saber, a posição original é o equilíbrio reflexivo; e o próprio desenho da posição original é construído com base no equilíbrio reflexivo, com base em nossos juízos ponderados de justiça. A ideia básica da teoria da justiça é que se concordamos com um procedimento, considerado justo à luz de nossos juízos ponderados de justiça, qualquer resultado oriundo desse procedimento é justo; se concordamos com a posição original e as restrições impostas às partes visando garantir a imparcialidade, também teríamos que concordar com os princípios de justiça escolhidos nessa situação hipotética.

\section{Considerações finais}

Para concluir, a suposta plausibilidade da aplicação da objeção schopenhauriana do egoísmo contra a ética de Kant também à justiça como equidade refere-se não a presença do egoísmo propriamente dita no raciocínio das partes, mas antes, numa suposta inconsistência entre a intenção manifesta do defensor da respectiva ética (seja o construtivismo kantiano, seja o construtivismo político) de que o procedimento de teste de máximas no caso de Kant e de 
escolha de princípios de justiça no caso de Rawls seja por si mesmo suficiente para identificar as regras morais e imorais. A ética de Kant supostamente seria vulnerável a esse tipo de objeção porque quem discrimina as máximas morais e imorais no fundo seria o princípio da reciprocidade e o egoísmo, o que consistiria em uma gritante heteronomia da vontade, e não o critério de ausência de contradição na vontade e na concepção de uma máxima moral. No caso da justiça como equidade a discriminação seria feita, não pelo próprio procedimento de escolha orientado apenas com base na racionalidade autointeressada das partes, mas antes restrições externas a esse mesmo procedimento, o que parece ecoar as críticas de Ronald Dworkin, em seu artigo The Original Position, à posição original rawlsiana, a saber, que Rawls somente consegue derivar os princípios de justiça na posição original porque já introduziu sorrateiramente seu conteúdo entre as premissas, que são as suas próprias convicções normativas que servem para moldar a própria posição original. Não obstante, Rawls ainda poderia tentar argumentar em sua defesa sustentando que a justiça como equidade incorpora dois tipos de justificação e não apenas a posição original. Ela também possui o que ele denomina de equilíbrio reflexivo, o qual consiste em uma mutua ponderação entre princípios gerais e intuições particulares. Chamar a atenção para isso poderia ser considerado um tipo de resposta à crítica da suposta inconsistência e à suposta concepção atomista de pessoa, totalmente separada de seus laços sociais porque, de um lado, mostra que Rawls não desconsidera as intuições normativas compartilhadas das sociedades em que vivemos (por isso não seria uma concepção atomista de pessoa, mas antes, uma concepção de pessoa como livre e igual intersubjetivamente difundida nas sociedades pluralistas democráticas e liberais contemporâneas); de outro lado, aparentemente mostraria que o conteúdo dos princípios de justiça, supõe-se desde a elaboração da justiça como equidade, não são o resultado apenas da escolha racional mutuamente desinteressada e egoísta das partes, uma vez que Rawls entende que os princípios de justiça escolhidos na posição original teriam que concordar com nossos juízos ponderados de justiça em equilíbrio reflexivo. Obviamente, uma questão ainda permanece a ser explicada: no final das contas, para que serve a posição original, se o critério último são os juízos ponderados de justiça? A isso, a resposta de Rawls talvez fosse que em sociedades pluralistas como as nossas, em que há uma grande divergência acerca de questões de justiça básica, a construção do experimento da posição original orientado pelos nossos juízos ponderados de justiça teria uma função de convencimento e esclarecimento de quais são os princípios de justiça independentemente das intuições, em apresentar-se como uma concepção de justiça procedimental pura, na qual concordando com as condições do procedimento, seríamos levados aceitar o que resultasse desse procedimento com que concordamos. A 
imparcialidade do procedimento garantiria uma decisão imparcial entre os princípios disponíveis. É claro que aqui se poderia perguntar: o que garante que o procedimento é justo e imparcial senão as intuições normativas que já possuímos? E, como essas intuições são externas ao próprio procedimento, a acusação de inconsistência entre intenção explícita e o que realmente ocorre quando da aplicação do mecanismo hipotético da posição original, a qual eu compreendo ser um elemento central da crítica de Schopenhauer ao princípio máximo da ética Kant, parece assombrar a justiça como equidade novamente.

\section{Referências Bibliográficas}

ANSCOMBE, G. E. M. "Modern Moral Philosophy". In: Philosophy, Vol. 33, N. 124 (jan 1958), p. 1-19.

DWORKIN, R. "The Original Position". In: DANIELS, N. Reading Rawls. Critical studies in Rawls $A$ theory of justice. Stanford: University Press, 1989. p. 16-53.

HEGEL, G. W. F. Grundlinien der Philosophie des Rechts. Stuttgart: Reclam, 2009.

KANT, I. Fundamentação da Metafísica dos Costumes. Trad. Paulo Quintela. Lisboa: Edições 70.

\section{. Die Metaphysik der Sitten. Frankfurt: Reclam, 2007.}

MACINTYRE, A. After Virtue: A Study in Moral Theory. Third Edition. Notre Dame: University of Notre Dame Press, 2007.

NUSSBAUM, M. "Rawls and Feminism". In: Cambridge Companion to Rawls. Cambridge: Cambridge University Press, 2003.

RAWLS, J. A Theory of Justice. Revised Edition. Cambridge: Harvard University Press, 1999.

. Political Liberalism. New York: Columbia University Press, 1993.

SCHOPENHAUER, A. Über die Grundlage der Moral. Hamburg: Felix Meiner, 2007.

- Sobre o Fundamento da Moral. Trad. Maria Lúcia Mello Oliveira Cacciola. São Paulo: Martins Fontes, 2001. 